- Mandibular repositioning splints can be used to treat the symptoms of sleep-related breathing disorders with high rates of compliance and highly positive reported treatment outcome.

- Much of the suffering caused by sleep-related breathing disorders is borne by the sleeping partner.

- The majority of patients experience only mild, reversible side effects during MRS therapy.

\title{
Patients' and sleeping partners' experience of treatment for sleep-related breathing disorders with a mandibular repositioning splint
}

\author{
C. J. Bates ${ }^{1}$ and J. P. McDonald ${ }^{2}$
}

Aim To determine in detail the complications associated with the use of mandibular repositioning splints (MRS) to treat sleep-related breathing disorders.

Method This prospective cross-sectional cohort study audits the management with mandibular repositioning splints of 121 patients suffering from sleep-related breathing disorders. Investigation of patients' and sleeping partners' perspectives on treatment was undertaken with the use of a questionnaire based study.

Results Sixty-eight per cent of respondents reported that they were compliant with treatment; various side effects were reported of which excess salivation was the most common. Investigation of sleeping partners' perspectives revealed that 70\% felt that their partners' snoring was improved and 47\% felt that their partner's breathing pauses during sleep were reduced. Sixty-four per cent of the sleeping partners also reported that their own sleep pattern had improved since their partner's treatment.

Conclusion Mandibular repositioning splints used in the manner described by this paper are demonstrated to have a good compliance rate, provide successful treatment and exhibit only minor, reversible side effects.

\section{INTRODUCTION}

Obstructive Sleep Apnoea Hypopnoea Syndrome (OSAHS) is a recognised clinical disorder in which there is repeated narrowing and collapse of the upper airway during sleep, causing cessation of breathing to occur in the presence of inspiratory effort. ${ }^{1,2}$ Sleeprelated breathing disorders exist as a continuum which ranges from simple snoring to sleep degradation and OSAHS, which in extreme circumstances may be life threatening.

Sleep clinics in the United Kingdom first began to treat substantial numbers of OSAHS patients in the early 1980s. The condition

\footnotetext{
1*Specialist Registrar in Orthodontics, SIGN/SCPMDE Clinical Fellow, Orthodontic Department, Victoria Hospital, Fife; ${ }^{2}$ Consultant Orthodontist, Orthodontic Department, Victoria Hospital, Fife

*Correspondence to: Miss Claire Bates

Email:claire_bates@hotmail.com
}

\section{Refereed paper}

Accepted 23 Feb 2005

doi: $10.1038 /$ sj.bdj.4813149

๑) British Dental Journal 2006; 200: 95-101 has received increased recognition in recent years due to the multi-system complications associated with the syndrome and the significant prevalence in the adult population. ${ }^{3}$

One of the main indications for treatment is daytime sleepiness, which can result in the patient falling asleep at unexpected and inappropriate moments, while talking or eating or while stopped in a car at traffic lights. Sufferers may only be able to stay awake when constantly stimulated.

In Britain, the daytime sleepiness associated with OSAHS has been shown to be linked to impaired vigilance and driving performance. A study suggested that around 20\% of accidents on motorways in Leicestershire County were caused by motorists falling asleep. ${ }^{4}$ Alarmingly, 24\% of patients with OSAHS have been reported to fall asleep while driving at least once on a weekly basis. ${ }^{5}$ Thus physicians in the UK are required to advise patients with OSAHS that they should not drive until effective treatment has been established. ${ }^{6}$

Oral appliances were considered by Robin as a treatment for mandibular deficiency and upper airway obstruction as early as $1934 .^{7}$ Oral appliances of various designs have been proposed and are used increasingly in the treatment of snoring and mild to moderate sleep apnoea, and offer an attractive alternative to surgery or n-CPAP (nasally applied Continuous Positive Airway Pressure).

This study aimed to examine the use of mandibular repositioning splints (MRS) in the treatment of sleep-related breathing disorders, in order that the complications associated with their use may be determined in detail.

\section{MATERIAL AND METHODS}

\section{Subjects}

Adult patients were recruited prospectively as they were referred for treatment. Treatment was carried out by a single consultant orthodontist, between October 2001 and July 2002 in the Orthodontic Department of Victoria Hospital, Fife. No patients were excluded as it was felt important to gather data from all patients undergoing treatment, including the edentulous.

\section{Data collection}

Anthropometric data included age, gender and Body Mass Index (BMI). The Apnoea/Hypopnoea Index (AHI), an objective 


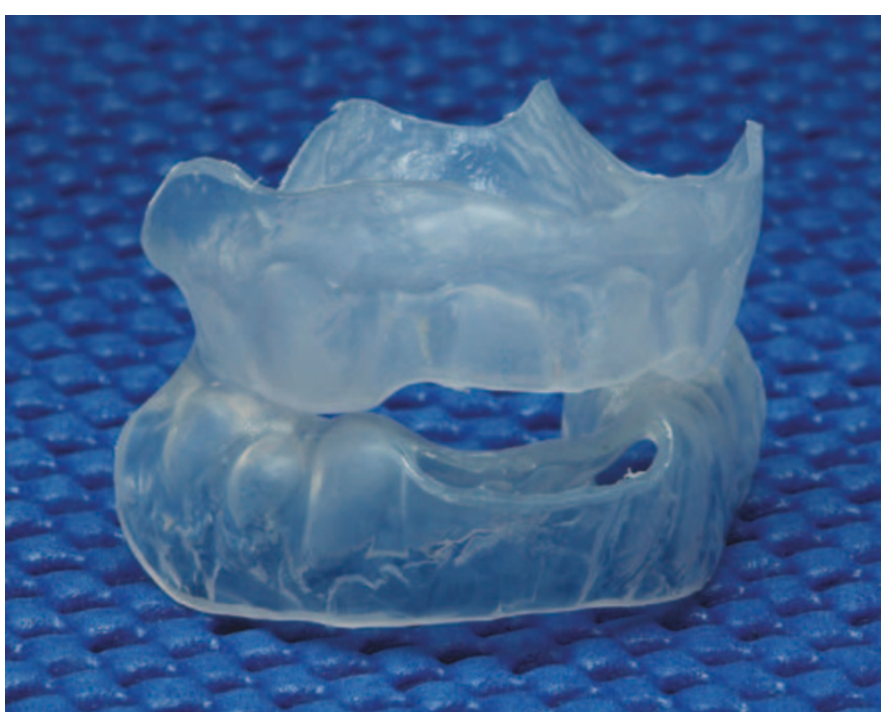

Fig. 1 Photograph of a vacuum formed mandibular splint

measure of OSAHS severity, was gathered from patients who had attended the Edinburgh Sleep Centre for overnight sleep study. Each subject and sleeping partner completed the Epworth Sleepiness Scale (ESS). Which is a simple, self-administered questionnaire providing the recognised standard subjective measure of the level of daytime sleepiness; it has a minimum score of 0 and a maximum score of $24 .^{8}$

\section{Statistical evaluation}

The data from this study were entered into a spreadsheet and analysed using SAS version $8 .^{9}$

\section{Appliance design}

All MRS were individually manufactured and custom fitted to produce $75 \%$ of the maximal comfortable mandibular protrusion and 2-4 mm inter-incisal clearance. The splints consisted of two vacuum formed mouthguards providing complete occlusal coverage, constructed from Kombiplast hard/soft (Dreve, Frankfurt, Germany), a bi-laminate ethylene-methylacrylate/polystyrene material. (Fig. 1) The two units were sealed in protrusion. Retention was by engagement of undercuts by the flexible material. Patients received both written and verbal instructions regarding the use of their device at their initial visit and again when fitting the device a week later.

\section{Questionnaire survey}

Each subject and sleeping partner completed the ESS at the initial visit and was then invited to complete a follow up postal questionnaire three months after provision of the appliance. The questionnaire repeated the standard ESS and subjects were asked to report on their compliance, experience of side-effects and perceived treatment outcome. These questions are detailed in Appendix 1. Standard quality of life questionnaires such as the SF36 may not be sensitive to some of the benefits of MRS treatment, so a questionnaire was developed specifically for the study in conjunction with a statistician. It was designed to be concise, using closed questions which would not require clarification from an examiner to increase the accuracy of interpretation of the results. Wherever possible questions were used that had appeared in previous published studies to enable comparison. . $^{10-13}$

An initial pilot study was carried out on 10 subjects who were not included in the study, to test the questionnaire's suitability. Minor alterations in terms of grammar were made to three of the questions to improve clarity.

\begin{tabular}{|c|c|c|c|c|}
\hline & Mean & Minimum & Maximum & SD \\
\hline Age (years) & 49.55 & 28.00 & 85.00 & 10.34 \\
\hline BMI (kg/m2) & 28.72 & 19.00 & 44.00 & 4.31 \\
\hline$\underline{\mathrm{AHI}}$ & 18.21 & 0 & 77.00 & 13.64 \\
\hline ESS & 9.41 & 0 & 22.00 & 5.24 \\
\hline
\end{tabular}

\begin{tabular}{|c|c|c|c|c|}
\hline \multirow[b]{2}{*}{ Mean Age (years) } & \multirow{2}{*}{$\begin{array}{c}\begin{array}{c}\text { Responders } \\
\mathrm{N}=92\end{array} \\
51.4\end{array}$} & \multirow{2}{*}{$\begin{array}{c}\begin{array}{c}\text { Non-Responders } \\
\mathbf{n}=\mathbf{2 9}\end{array} \\
\\
47.2 \\
\end{array}$} & \multicolumn{2}{|c|}{$\begin{array}{l}\text { Responders v } \\
\text { Non-Responders } \\
\text { 2-sided p value } \\
\text { Kruskal-Wallis }\end{array}$} \\
\hline & & & 0.07 & 0.07 \\
\hline Mean ESS & 9.7 & 8.7 & 0.24 & 0.23 \\
\hline \multirow[t]{2}{*}{ Mean AHI } & 17.9 & 14.0 & 0.91 & 0.89 \\
\hline & & & $\begin{array}{l}\text { Chi-S } \\
\text { Fishe }\end{array}$ & \\
\hline Male Sex (\%) & 68.0 & 70.5 & 0.78 & 0.83 \\
\hline
\end{tabular}

\section{RESULTS}

\section{Subjects}

One hundred and twenty one patients participated in the study; the ratio of males to females was 2.3 to 1 . The range of ages was normally distributed, with peak incidence during middle age. The Body Mass Indices of the cohort were also normally spread. The mean BMI was 28.7, classed as obese. (Table 1)

Ninety two subjects responded to the questionnaire, a response rate of $76 \%$. (Table 2) This is comparable to other response rates in the literature such as $73.7 \%$ achieved by Shadaba and $76 \%$ by McGown. ${ }^{12,14}$

Twelve responses were excluded as the subjects did not complete the questionnaire but returned it with a hand written letter commenting on their treatment. Some subjects failed to answer all of the questions resulting in a smaller number (n) of responders for some of the questions. There were 27 missing sets of values in the statistical analysis of sleeping partners $(n=53)$ as 27 of the 80 responders did not have partners available to complete the questionnaire. Subjects who failed to respond had two repeat mailings of the questionnaire and then attempts were made to contact the patients by telephone. Twelve patients could not be contacted, one subject died of a non apnoea related cause, one patient was hospitalised, and three appliances were lost. Those who responded showed no significant differences to any of the measured parameters when compared to those who did not respond. (Table 2)

Ten respondents $(n=78)$ had received past treatment for their sleep problem, of which four had undergone surgery and six had received n-CPAP, all of which had failed. No subjects were receiving any other form of treatment at the time of the study.

\section{MRS USE}

\section{Comfort}

Sixty nine percent of respondents reported that their appliance was comfortable within a month, of which $25 \%$ adapted within a week. (Table 3) The remaining 31\% reported that they felt unable to wear their appliance.

\section{Compliance}

Sixty eight percent of respondents $(n=80)$ reported that they were still wearing their appliance; the mean number of nights per week the appliance was worn was 5.6 and the mean number of hours per night the appliance was worn was 6.2. 


\section{Side effects of MRS use}

A large majority $(n=74)$ of subjects experienced one or more side effects, and four (5\%) of the subjects suffered all five side effect categories. (Fig. 2)

Excess salivation was the most commonly reported problem, with 34 out of $80(43 \%)$ respondents stating that it was a minor problem. Four (5\%) respondents found it was such a significant problem that they were unable to wear their appliance.

Intra-oral soreness was reported by $32(40 \%)$ respondents to be a minor problem and in seven (9\%) it resulted in the patient being unable to wear the appliance.

Jaw discomfort was encountered as a minor problem for 22 $(28 \%)$ respondents, but in nine patients $(11 \%)$ the problem was so significant it led to inability to wear the appliance.

Difficulty falling asleep or frequent awakening was a minor reported problem for $19(24 \%)$ respondents, where eight $(10 \%)$ found it so significant they were unable to wear their appliance.

Difficulty breathing was cited least commonly, 16 (20\%) respondents found it a minor problem and seven (9\%) found it so significant they were unable to use their appliance.

Waking up with appliance detached was a minor reported problem for 19 (24\%) respondents with eight (10\%) finding it so significant they were unable to wear the appliance.

\section{Reported treatment outcome}

Subjects were asked to report on the effects of their treatment (Fig. 3).

Sleep quality, $41(59 \%)$ respondents $(n=69)$ felt their sleep quality was improved and eight (10\%) felt that it was worse.

Snoring, $45(70 \%)$ of respondents $(n=64)$ to this question reported that their snoring was improved since treatment and one patient (1\%) felt that their snoring was worse.

Concentration, $19(29 \%)$ respondents $(n=65)$ felt that their concentration was improved, one respondent (1\%) felt it was worse.

Energy levels, $19(29 \%)$ respondents $(n=67)$ felt that their daytime energy level had improved and three (4\%) felt it was worse.

Breathing pauses, $20(36 \%)$ respondents $(n=55)$ felt that their breathing pauses during sleep were improved and three (5\%) felt that they were worse.

\section{Sleeping partners' perspectives}

Sleeping partners $(n=53)$ were asked to report on the effects of their snoring partners' treatment. (Fig. 4)

Daytime sleepiness was reported to be improved by 20 (37\%) responding partners, three $(6 \%)$ felt it was worse.

Snoring was reported to be improved by 37 (70\%) of responding partners, four (7\%) felt it was worse.

Moodiness was reported to be improved by 16 (31\%) responding partners $(\mathrm{n}=51)$, four $(7 \%)$ felt it was worse.

Breathing pauses were reported to be improved by 23 (47\%) responding partners $(n=49)$, two $(4 \%)$ felt they were worse.

\section{Partners' sleep change}

Sleeping partners were asked to report on the changes in their sleep since their partner began MRS therapy. (Table 4)

\section{DISCUSSION}

This is the first study to survey in detail both patient and sleeping partner experience of treatment for sleep-related breathing disorders with MRS.

\section{Subjects (Table 1)}

The male to female ratio of the cohort mirrored closely the level of OSAHS reported to exist in the population. ${ }^{3}$ The increased mean BMI was also expected as obese patients have been shown to have a higher incidence of OSAHS. ${ }^{10}$ Mean pre-treatment ESS

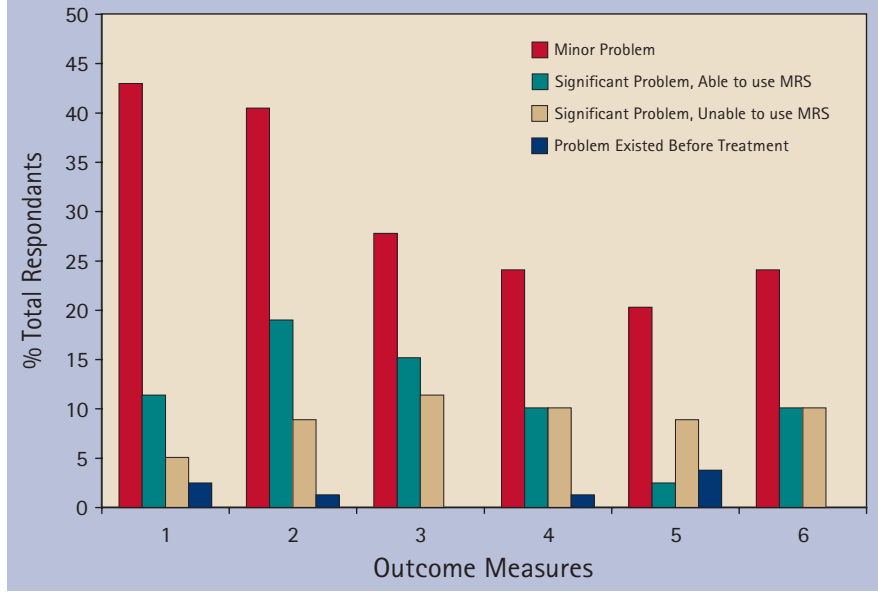

Fig. 2 Histogram 1 : side effects

Outcome measures: 1 = Excess salivation, 2 = Intra-oral pain, 3 = Jaw

discomfort, 4 = Difficulty falling asleep or frequent awakening, $5=$ Difficulty breathing, $6=$ Waking up with appliance detached.

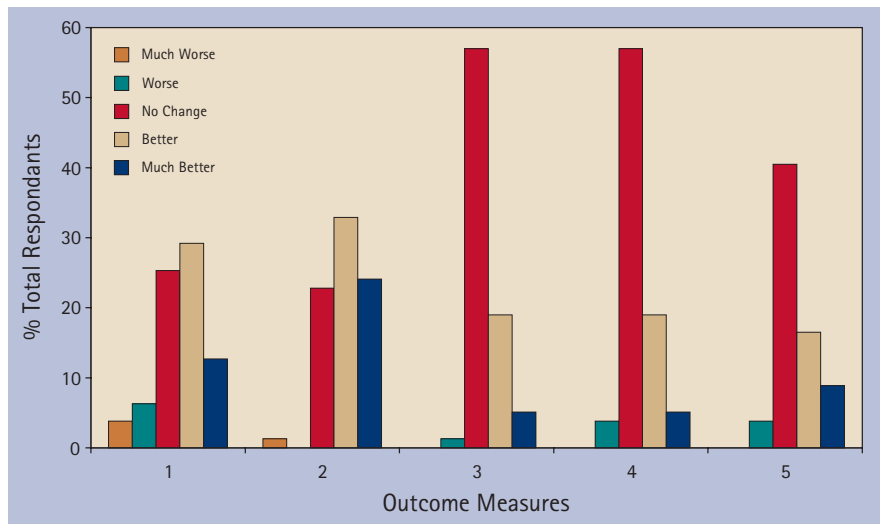

Fig. 3 Histogram 2: treatment outcome

Outcome measures: 1 = Sleep quality, 2 = Snoring,

3 = Concentration, 4 = Energy levels, 5 = Breathing pauses

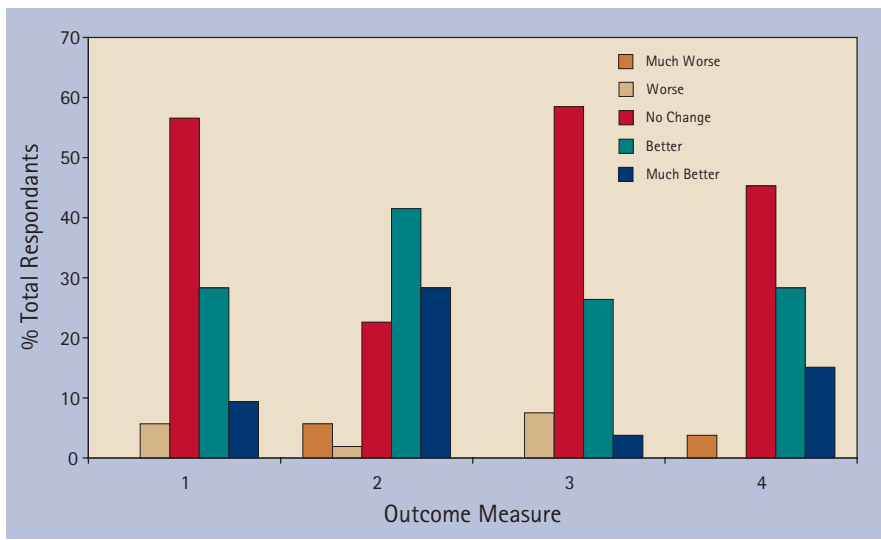

Fig. 4 Histogram 3: sleeping partners' view of treatment outcome

Outcome measures: 1 = Daytime sleepiness, 2 = Snoring,

3 = Moodiness, 4 = Breathing pauses

equated to mild to moderate OSAHS as defined by Johns in 1991. ${ }^{4}$ Mild to moderate cases have been shown to benefit the most from MRS treatment. ${ }^{11}$ Mean pre-treatment AHI was skewed towards lower values, in line with the referral pattern of mild to moderate cases for treatment with MRS.

MRS use (Table 3)

Sixty nine per cent of subjects found their MRS comfortable within a month. However, the remaining 31\% reported that they did not adapt during the period of the study. It is important to recognise that generally $40-50 \%$ of patients do not comply with 


\begin{tabular}{|c|c|c|}
\hline & Respondents $(n=79)$ & $\%$ Respondents \\
\hline Less than 7 days & 20 & 25 \\
\hline 1 to 2 weeks & 21 & 27 \\
\hline 2 weeks to 1 month & 13 & 17 \\
\hline Never & 25 & 31 \\
\hline
\end{tabular}

\begin{tabular}{|c|c|c|}
\hline & Respondents $(n=53)$ & \% Respondents \\
\hline Much worse & 3 & 5.7 \\
\hline Worse & 3 & 5.7 \\
\hline No change & 13 & 24.5 \\
\hline Better & 21 & 39.6 \\
\hline Much better & 13 & 24.5 \\
\hline
\end{tabular}

any treatment as prescribed, and that compliance is not associated with age, sex, education, economic status, or disease characteristics. ${ }^{15}$ Data on long term MRS compliance are limited, with a range of 52-100\% reported. ${ }^{10,13,14,16}$

Schmidt-Nowara in 1995 reported that patients must receive initial written instruction to produce the best rates of compliance; hence in this study patients were given written instructions at their initial visit and on fitting the MRS. ${ }^{10}$

The compliance rate of 68\% achieved is comparable with results of other studies such as 75\% achieved by Schmidt-Nowara in $1995,{ }^{10}$ and $76 \%$ achieved by Johal in $1999 .{ }^{11}$

\section{Side-effects (Fig. 2)}

Initial side-effects associated with MRS may prevent early acceptance of the device and contribute to non-compliance. Other published studies documenting side-effects experienced during MRS treatment also report a number of patients suffering one or more side-effects; in this study 5\% of subjects reported all side-effect categories. ${ }^{10,12,13,17}$

Excess salivation was the most frequently reported side-effect, in agreement with the findings of a recent randomised clinical trial published by Johnston et al. ${ }^{13}$ This is to be expected in the first week of appliance wear, but diminishes after a few days of wear. ${ }^{10,12,18}$ Soreness was also frequently reported but may be dealt with by simple adjustment of the appliance.

Difficulty falling asleep or frequent awakening and difficulty in breathing were reported but less frequently. Waking up to find the appliance detached was also less of a problem in this study than in other reported studies using the same appliance design; Johnston reported that $84 \%$ of his subjects found their appliance came out of their mouth when asleep on two nights per week or less. ${ }^{13}$

Discomfort of the temporomandibular joint was reported by $54 \%$ of patients which is comparable to other figures found in contemporary literature. ${ }^{10,12,13}$ This may be minimised by careful assessment of the degree of mandibular protrusion. ${ }^{12}$ It may be wiser in practice to advance the mandible to the maximum comfortable position rather than by a standard amount such as $75 \%$ of the maximum as is often described. ${ }^{13}$

\section{Treatment outcome (Fig. 3)}

Objective treatment outcome for use of MRS has been reported by recent randomised controlled trials. ${ }^{13,19}$ Patient experience of this treatment is an area requiring further clarification. MRS treatment is reported by a large proportion of patients to be successful in improving their quality of night time sleep. Concentration, energy levels and breathing pauses are also reported improved for many. The symptom with the largest reported improvement in this study was snoring (70\%). This result compares with other published work in which treatment of snoring has been assessed. Studies show a considerable improvement in symptoms for a significant proportion of patients. ${ }^{10}$ For example Johal's 1999 study which found 76\% of respondents reported an improvement in snoring and daytime sleepiness. ${ }^{11}$

\section{Partners' views (Fig. 4 and Table 4)}

Much of the suffering associated with sleep-related breathing disorders is borne by the sleeping partner as the patient is asleep. There is a lack of evidence on the impact snoring has on the partner; partners have been asked to report on their snoring partner but seldom about their own suffering. ${ }^{13}$

Sleeping partners may give a more accurate reflection of the improvement in the subjects' snoring and can add further understanding to the improvement in other symptoms, such as moodiness, which is known to increase in OSAHS sufferers and which improved in around a third of subjects in this study. ${ }^{2}$

Seventy per cent of sleeping partners reported their partners' snoring had improved using MRS; this confirms the snorers' own reported experience of 70\% improvement. Partners also reported greater incidence of improvement in the number of breathing pauses than the patient themselves, perhaps a more accurate reflection.

Sleeping partners reported on changes to their night time sleep since treatment of their partner. Sixty-four per cent felt their sleep was improved; a two-thirds improvement in night time sleep for sleeping partners represents a significant positive change, and has considerable social impact.

\section{Limitations}

As with other surveys available, the questionnaire assessed compliance rates and satisfaction after a relatively short period of time compared to the average life span of a snoring patient. ${ }^{10,11,18}$ It would be useful to undertake another study with the same cohort after a period of one year and again at a fiveyear interval, hence allowing examination of long-term compliance rates and the success of treatment.

\section{Management decisions}

In the treatment of sleep-related breathing disorders no currently available modality provides the ideal combination of a high rate of success and patient acceptance without complications. Nasal CPAP has become the gold standard for significant OSAHS due to its efficacy, but patient acceptance and compliance are significant reported problems. ${ }^{19}$ Tracheostomy is the only other treatment with an efficacy comparable to CPAP, but given the range of alternatives, few patients choose a treatment option requiring a permanent prosthesis in the neck.

Oral appliances have been found to have a better success rate than soft tissue surgery. ${ }^{20}$ Compared to protriptylene, the principle medication used for OSAHS, oral appliances are more effective and the side effects more tolerable. ${ }^{10}$ When compared to weight loss, the effect of oral appliances is realised more quickly and the rate of success higher. Hence oral appliances although producing lower reported rates of AHI reduction, offer an acceptable alternative to CPAP, ${ }^{10}$ especially in mild to moderate cases of OSAHS.

The combination of side effects, reversibility and cost compares favourably to any other treatment for mild to moderate OSAHS. Oral appliance therapy for sleep-related breathing disorders is simple, reversible, portable, quiet and cost effective. It may be used in patients who are unable to tolerate n-CPAP or who are a poor surgical risk, when their effectiveness should be evaluated with the use of a sleep study after fitting the appliance. 


\section{CONCLUSIONS}

1. Snoring and the symptoms of OSAHS can be treated with MRS successfully with high rates of patient satisfaction.

2. A partner's perception of improvements in OSAHS or snoring following treatment with MRS can differ to that of the sufferer.

3. Subjective improvements in sleeping partners' sleep are seen if their partner is treated with MRS.

4. The majority of patients experienced mild side effects during MRS therapy.

5. A high compliance rate was obtained with no serious complications reported.

1. Battagel J. Obstructive sleep apnoea: Fact not fiction. Br DentJ 1996: 23: 315-324.

2. Guilleminault C. Obstructive sleep apnoea. The clinical syndrome and historical perspective. Med Clin NAm 1985; 69: 6 .

3. Young T M, Dempsey J, Skatrud J, et al. The occurrence of sleep disordered breathing among middle-aged adults. New Eng J Med 1993; 328: 1230-1235.

4. Semple S J G, Gibson G J. Sleep apnoea and related conditions. JRCP 1993; 27: 363-364.

5. Terran-Santos J. The association between sleep apnoea and the risk of traffic accidents. New Engl J Med 1999; 340: 847-851.

6. Taylor J F. Medical aspects of fitness to drive: a guide for medical practitioners. Medical Commission on Accident Prevention. London: HMSO, 1995.

7. Robin P. Glossoptosis due to atresia and hypertrophy of the mandible. Am J Dis Child 1934; 48: 541-547.

8. Johns M W. A new method for measuring daytime sleepiness: The Epworth Sleepiness Scale. Sleep 1991; 14: 540-545.
9. SAS version 8. (C) 2002 SAS Institute, SAS Campus Drive, Cary, North Carolina 27513 USA.

10. Schmidt-Nowara W, Lowe A, Wiegand L. An American Sleep Disorders Association review. Oral appliances for the treatment of snoring and obstructive sleep apnoea: review. Sleep 1995; 8: 501-510.

11. Johal A, Battagel J M. Current principles in the management of obstructive sleep apnoea with mandibular advancement appliances. Br Dent J 2001; 190: 532-536.

12. Shadaba A, Battagel J M, Owa $A$, et al. Evaluation of the Herbst mandibular advancement splint in the management of patients with sleep related breathing disorders. Clin Otolaryngol 2000; 25: 404-412.

13. Johnston C D, Gleadhill I C, Cinnamond M J. Mandibular advancement appliances and obstructive sleep apnoea: a randomized clinical trial. EJO 2002; 24: 251-262.

14. McGown A D, Makker H K, Battagel J M, L'Estrange P R. Long-term use of mandibular advancement splints for snoring and obstructive sleep apnoea: a questionnaire survey. EResp J 2001; 17: 462-466.

15. Grunstein R R. Nasal Continuous Positive Airway Pressure treatment for obstructive sleep apnoea. Thorax 1995; 50: 1106-1111.

16. Clark G T, Arand D, Chung E, Tong D. Effect of anterior mandibular positioning on obstructive sleep apnoea. Am Rev Respir Dis 1993; 147: 624-629.

17. Mehta A, Qin J, Petocz $P$, et al A randomized, controlled study of a mandibular advancement splint for obstructive sleep apnoea. AJRCCM 2001; 163: 1457-1461.

18. Sullivan C E, Issa F G, Berthon-Jones M, Eves L. Reversal of obstructive sleep apnoea by Continuous Positive Airway Pressure applied through the nares. Lancet 1981 1:862-865

19. Engleman H M, McDonald J P, Graham D et al. Randomized crossover trial of two treatments for sleep apnoea/hypopnoea syndrome. Continuous Positive Airway Pressure and mandibular repositioning splint. AJRCCM 2002; 166: 855-859.

20. Wilhelmsson $B$, Tegelberg $A$, Walker-Engstrom $M L$ et al. A prospective randomised study of a dental appliance compared with uvulopalatopharyngoplasty in the treatment of obstructive sleep apnoea. Acta Oto-Laryng 1999; 119: 503-509.

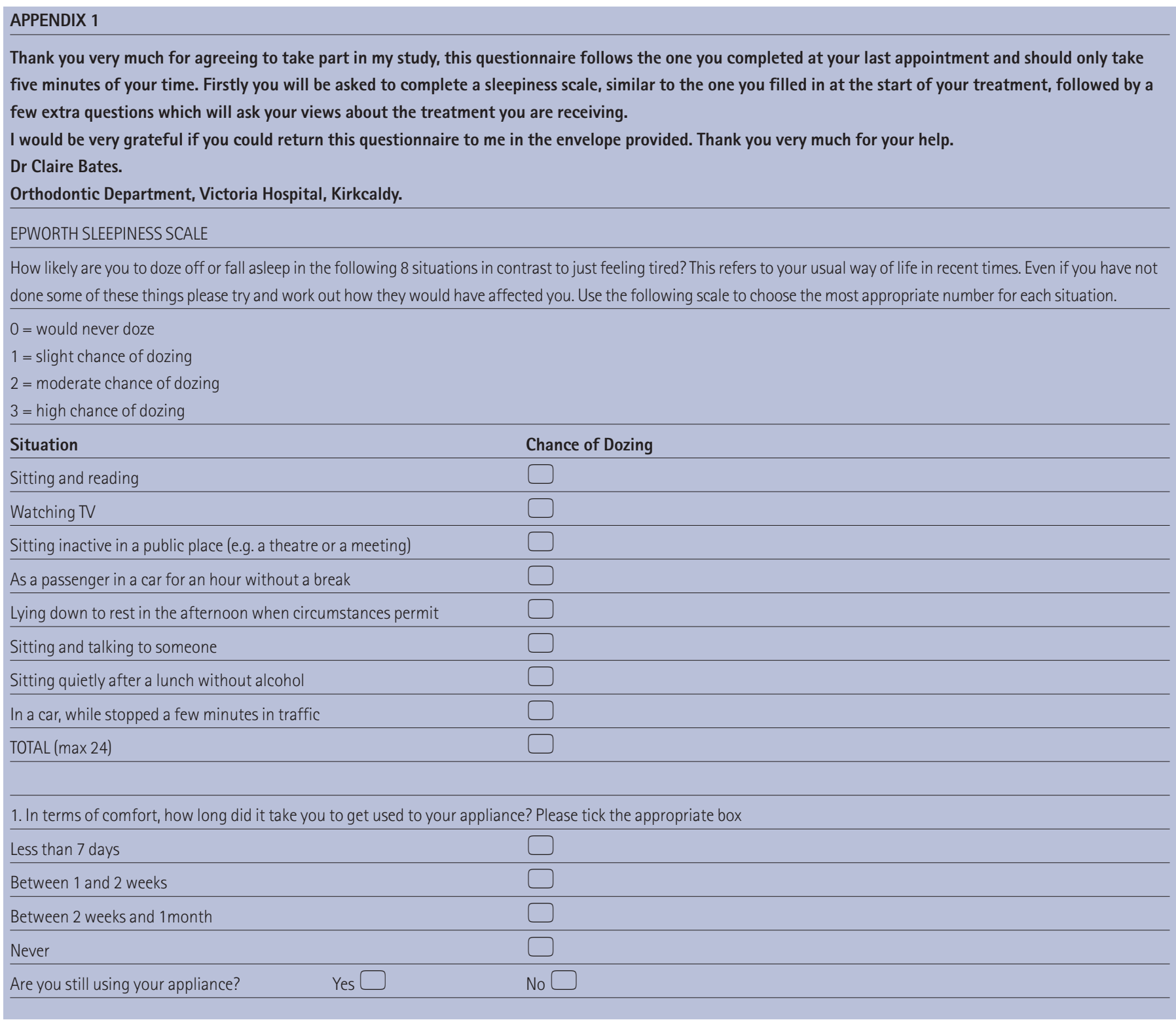




\section{RESEARCH}

2. If yes, please enter in the box the number of nights per week you currently use your appliance?

3. On these nights, please enter the average number of hours that your appliance is worn.

4. If you have stopped wearing or decreased the amount you wear the appliance, please could you indicate when and why you did so?

5. Occasionally people may experience problems or side effects with the treatment.

Please tick a box to indicate if you have encountered any of these problems and how severe the problem was.

\begin{tabular}{|c|c|c|c|c|}
\hline & Minor Problem & $\begin{array}{l}\text { Significant problem } \\
\text {-still using appliance }\end{array}$ & $\begin{array}{l}\text { Significant problem } \\
\text {-unable to use appliance }\end{array}$ & $\begin{array}{l}\text { Problem I had before } \\
\text { treatment }\end{array}$ \\
\hline Excess salivation & $\square$ & $\square$ & $\square$ & $\square$ \\
\hline $\begin{array}{l}\text { Soreness of mouth } \\
\text { /teeth/gums }\end{array}$ & $\square$ & $\square$ & $\square$ & $\square$ \\
\hline Jaw discomfort & $\square$ & $\square$ & $\square$ & $\square$ \\
\hline $\begin{array}{l}\text { Difficulty falling asleep } \\
\text { /frequent awakening }\end{array}$ & $\square$ & $\square$ & $\square$ & $\square$ \\
\hline Difficulty breathing & $\square$ & $\square$ & $\square$ & $\square$ \\
\hline $\begin{array}{l}\text { Waking up+appliance is } \\
\text { detached from teeth } \\
\text { lout of mouth }\end{array}$ & $\square$ & $\square$ & $\square$ & $\square$ \\
\hline
\end{tabular}

6. Please tick a box to indicate whether treatment with your appliance has made any difference to the following.

\begin{tabular}{|c|c|c|c|c|c|}
\hline & Much worse & Worse & No change & Better & Much better \\
\hline $\begin{array}{l}\text { Quality of night } \\
\text { time sleep }\end{array}$ & $\square$ & $\square$ & $\square$ & $\square$ & $\square$ \\
\hline Snoring & $\square$ & $\square$ & $\square$ & $\square$ & $\square$ \\
\hline Concentration & $\square$ & $\square$ & $\square$ & $\square$ & $\square$ \\
\hline Energy levels & $\square$ & $\square$ & $\square$ & $\square$ & $\square$ \\
\hline $\begin{array}{l}\text { Breathing pauses } \\
\text { during sleep }\end{array}$ & $\square$ & $\square$ & $\square$ & $\square$ & $\square$ \\
\hline
\end{tabular}

7. Have you had any other form of treatment for your sleep problem?

8. If Yes, please specify the type: $\square$ C.P.A.P $\square$ Laser Surgery $\square$ surgery $\square$ other

If other please state treatment received

Thank you very much for completing my questionnaire. If you have a spouse or partner, I would be grateful if you could ask him/her to complete the last section independently, without consulting you.

\section{PARTNER QUESTIONNAIRE}

Thank you very much for agreeing to take part in my study, this questionnaire should only take two minutes of your time.

Firstly you will be asked to complete a sleepiness scale, similar to the one you may have filled in at the start of your partners' treatment, followed by a few extra questions which will ask your views about the treatment they are receiving. The following questions refer to your partner-who is using the snoring appliance.

\section{EPWORTH SLEEPINESS SCALE}

How likely was your partner to doze off or fall asleep in the following 8 situations in contrast to just feeling tired, before starting treatment with their appliance? And how likely are they to do so since starting their treatment.

These questions refer to his/her usual way of life both before and since starting treatment. Even if he/she has not done some of these things please try and work out how may have affected him/her now and in the past. 
Please use the following scale to choose the most appropriate number for each situation.

$0=$ would never doze

1 = slight chance of dozing

2 = moderate chance of dozing

3 = high chance of dozing

Situation

Chance of Dozing

Sitting and reading
Watching TV
Sitting inactive in a public place (e.g. a theatre or a meeting)
Lying down to rest in the afternoon when circumstances permit
Sitting and talking to someone
Sitting quietly after a lunch without alcohol
TOTAL (max 24)

TOTAL $(\max 24)$

Please tick a box to indicate if there have been any changes to the following aspects of your partner's health since the start of their treatment.

Daytime sleepiness
Snoring
Moodiness/irritability
Breathing pauses
during sleep

The final question refers to you.

Please tick a box to indicate if there have been any changes in your night time sleep since your partner started to use their appliance.

Much worse Worse
$\begin{aligned} & \text { Quality of your night } \\ & \text { time sleep }\end{aligned}$

Thank you very much for completing my questionnaire. I would be very grateful if you could return this questionnaire to me in the envelope provided. 